\title{
POLÍTICAS DE INCLUSÃO ESCOLAR NO BRASIL E EM PORTUGAL: DESAFIOS PARA A JUSTIÇA CURRICULAR
}

\author{
Cléia Demétrio Pereira ${ }^{(*)}$ \\ Geovana Mendonça Lunardi-Mendes (*) \\ José Augusto de Brito Pacheco ${ }^{(* *+)}$
}

As políticas de inclusão escolar têm sido disseminadas em muitos países, como Brasil e Portugal, signatários dos acordos com a Declaração Mundial de Educação para Todos (UNESCO, 1990), Declaração de Salamanca (UNESCO, 1994) e Convenção Internacional das Nações Unidas sobre os Direitos das Pessoas com Deficiência (ONU, 2006), que, dentre outros, orientam a instituição de políticas nacionais de educação inclusiva. Sinalizam-se essas políticas internacionais, justamente porque suas recomendações textuais são ratificadas e publicadas nos documentos oficiais desses dois países.

A adoção dos acordos oficializados pelos protocolos de assinaturas, com a Organização das Nações Unidas para a Educação, Ciência e Cultura (UNESCO) e Organização das Nações Unidas (ONU), condiciona os governos a assumirem responsabilidades específicas na escolarização de todos os estudantes, principalmente àqueles que apresentam necessidades educativas especiais (NEE), mais especificamente, com deficiência. Estas políticas têm mobilizado dezenas de outros países e gerado o consenso entre eles à implantar políticas nacionais voltadas para a educação inclusiva em seus sistemas educativos, de modo a contemplar programas educacionais que viabilizem na prática a promoção na escolarização de todos os estudantes.

Nessa direção, este texto objetiva analisar documentos políticos vigentes no Brasil e em Portugal que regulamentam a organização da escolarização de alunos com deficiência da educação básica na perspectiva da educação inclusiva, e articulam a diferenciação curricular, como desafio a enfrentar e garantir a justiça curricular.

Compreende-se a justiça curricular no movimento que envolve a tomada de decisões sobre o currículo, desde a elaboração até sua atuação nas práticas curriculares, como a possibilidade de

\footnotetext{
${ }^{(*)}$ Doutoranda em Educação pela Universidade do Minho, mestre em Educação e Professora do Centro de Educação a Distância da Universidade do Estado de Santa Catarina.E-mail: cleia.demetrio@gmail.com.

${ }^{(* *)}$ Doutora em Educação, professora titular do Centro de Ciências da Educação e do Programa de Pós-graduação da Universidade do Estado de Santa Catarina (UFSC).E-mail: geolunardi@gmail.com.

${ }^{(* * *)}$ Professor catedrático, presidente do Instituto de Educação e Investigador do Centro de Investigação em Educação da Universidade do Minho. E-mail: jpacheco@ie.uminho.pt.
} 
desenhar um currículo contra-hegemônico, que vise minimizar as desigualdades presentes nos percursos de escolarização dos alunos (CONNELL, 1997; SILVA, 2018), especialmente, dos que apresentam deficiência.

Utilizou-se a pesquisa documental para o levantamento dos documentos políticos de inclusão de ambos os países, entre os anos de 2008 e 2016, com base na análise de conteúdo pelo procedimento da "análise temática" (BARDIN, 2009). Extraiu-se dos textos políticos os significados que deram sentido às temáticas sobre 'políticas de inclusão escolar'; 'diferenciação curricular' e 'justiça curricular e escolarização'. Seguimos as contribuições de Ball, Maguire, Braun (2016) para compreender a tradução e interpretação dos textos políticos, principalmente, pela atuação dos atores que escrevem e os que colocam em movimento/ação, considerando suas culturas e experiências, pois é nesse movimento que "as políticas tornam-se "vivas" e atuantes (ou não)" na educação básica.

No Brasil, os desdobramentos políticos para a inclusão escolar estão vinculados à implantação das salas de recursos multifuncionais ${ }^{1}$ (SRM) para o atendimento educacional especializado (AEE), identificadas como serviços especializados, capazes de responder às mais variadas diversidades que constituem a sala de aula, mediadas pela presença de recursos tecnológicos (BRASIL, 2008a, 2009b, 2011). Em Portugal, as diretrizes curriculares (PORTUGAL, 1986, 2008a) apontam para a inclusão dos alunos com NEE em projetos de formação mais abrangentes no contexto de cada escola, a partir de políticas de diversificação e diferenciação curricular (PORTUGAL, 2008a).

A convergência das políticas internacionais (BALL, 2001) tem influenciado, marcadamente, a condução das políticas nacionais na perspectiva da educação inclusiva, desde a década de 1990, mediante os desdobramentos de documentos legais, que recomendam decisões que justificam a garantia da justiça curricular aos estudantes com deficiência na escola comum. Entretanto, concluise que o acesso aos conhecimentos escolares ainda é um desafio da contemporaneidade, já que este direito ainda não está garantido para todos.

\section{POLÍTICAS DE INCLUSÃO ESCOLAR EM CONTEXTOS NACIONAIS: QUAIS PRESCRIÇÕES PARA A ESCOLARIZAÇÃO DE ALUNOS COM DEFICIÊNCIA?}

O levantamento dos documentos políticos de inclusão escolar realizado nos contextos brasileiro e português teve a finalidade de identificar as possíveis prescrições que direcionam a

\footnotetext{
1 A Portaria Ministerial SEESP/MEC 13/2007 foi o primeiro documento oficial que regulamentou a criação do Programa de Implantação de SRM e definiu os critérios de aquisição pelas redes de ensino comum (BRASIL, 2007).
} 
organização da escolarização de alunos com deficiência. A identificação dos documentos foi delimitada no período entre 2008 e 2016, considerando que em 2008 Brasil e Portugal tiveram publicação de políticas nacionais que demarcaram diretrizes e princípios da educação especial, na perspectiva de educação inclusiva, subsidiadas pelas políticas internacionais.

A localização dos documentos legais entre leis, decretos, resoluções, portarias, notas técnicas etc. foi realizada pelos sites $^{2}$ dos Ministérios de Educação dos países pesquisados, sendo selecionados os documentos que continham conceitos ou terminologias voltadas à educação especial, educação inclusiva, inclusão escolar, adaptação curricular, e, principalmente, as referenciadas à diferenciação curricular, questão que nos deteremos com maior ênfase, sob a análise do que tem sido prescrito e executado em nível local.

No âmbito português, nove documentos foram identificados, os quais compuseram o quadro das políticas de inclusão em Portugal.

Quadro 1. Identificação das políticas nacionais de inclusão escolar em Portugal (2008-2016)

\begin{tabular}{|c|c|}
\hline $\begin{array}{c}\text { ANO DE } \\
\text { PUBLICAÇÃo }\end{array}$ & DOCUMENTOS IDENTIFICADOS \\
\hline 2015 & Portaria 201-C/2015. \\
\hline 2015 & Resolução da Assembleia da República 17/2015. \\
\hline 2012 & Decreto-Lei 176/2012. \\
\hline 2011 & Parecer 1/2011. \\
\hline 2009 & Decreto-Lei 281/2009. \\
\hline 2009 & Resolução da Assembleia da República 57/2009. \\
\hline 2009 & Resolução da Assembleia da República 56/2009. \\
\hline 2008 & Lei 21/2008. \\
\hline 2008 & Decreto-Lei 3/2008. \\
\hline
\end{tabular}

Fonte: Elaborado a partir do site <http://www.dge.mec.pt/legislacao-e-circulares>.

Verificou-se que esse quadro de documentos políticos faz referência sobre a organização dos processos escolares de alunos com NEE que frequentam o sistema de ensino português. Desses, destacam-se a Portaria 201-C/2015 (PORTUGAL, 2015b), a Resolução da Assembleia da República 17/2015 (PORTUGAL, 2015a) e a Lei 21/2008 (PORTUGAL, 2008b) que alteram o Decreto-Lei 03/2008 (PORTUGAL, 2008a), quanto ao Currículo Específico Individual (CEI) e a transição para a vida pós-escolar desses estudantes.

\footnotetext{
${ }^{2}$ A realização das buscas nos sites dos Ministérios da Educação em Portugal e no Brasil ocorreu no decorrer do segundo semestre de 2016 e primeiro semestre de 2017.
} 
O Decreto-Lei 176/2012 (PORTUGAL, 2012a) amplia e regulamenta a escolarização obrigatória de crianças e jovens entre 6 e 18 anos, indicando adequações referentes as matrículas no ensino secundário, de estudantes contemplados pelo CEI. O Decreto-Lei 281/2009 (PORTUGAL, 2009c) cria o Sistema Nacional de Intervenção Precoce na Infância (SNIPI) em escolas referências, com intervenção sempre que a criança frequente a educação pré-escolar, articulado com serviços de saúde e de segurança social. Importa salientar que essas medidas (PORTUGAL, 2012a; 2009c) refletem, de algum modo, nos processos de ensino e aprendizagem de alunos com NEE, que preveem atenção específica desde a educação infantil ao secundário, no sistema educativo português.

Verificou-se que a Resoluções da Assembleia da República 56/2009 e 57/2009 (PORTUGAL, 2009a, 2009b) aprovam a Convenção dos Direitos das Pessoas com Deficiência e o Protocolo Opcional, respectivamente. Esses documentos ratificam o direito das pessoas com deficiência nos diferentes espaços sociais de Portugal, dentre eles o da educação, nos moldes do documento internacional, como prevê a ONU.

Dessa seleção, o Decreto-Lei 3/2008 (PORTUGAL, 2008a) foi o documento que deu maior visibilidade nas definições das prescrições referente a escolarização de alunos com deficiência. Este Decreto reitera a educação inclusiva pelo viés da equidade educativa e garantia de igualdade, quanto ao acesso e aos resultados da escolarização, pela definição dos apoios especializados prestados na educação pré-escola, no ensino básico e secundário da rede pública, particular e cooperativa,

[...] visando a criação de condições para a adequação do processo educativo às necessidades educativas especiais dos alunos com limitações significativas ao nível da atividade e da participação num ou vários domínios de vida, decorrentes de alterações funcionais e estruturais, de carácter permanente, resultando em dificuldades continuadas ao nível da comunicação, da aprendizagem, da mobilidade, da autonomia, do relacionamento interpessoal e da participação social. (PORTUGAL, 2008a, p. 155).

Considerando o interesse voltado à escolarização de estudantes com deficiência matriculados no primeiro ciclo do ensino básico, constatou-se que os apoios especializados estão submetidos às diretrizes curriculares que norteiam os projetos de formação abrangentes de cada escola e agrupamento de escolas, incluindo "adequações relativas ao processo de ensino e de aprendizagem, de carácter organizativo e de funcionamento" (PORTUGAL, 2008a, p. 155). Tais apoios encontram-se estruturados em escolas referências para a educação bilíngue de estudantes 
surdos, cegos e baixa visão, e, em unidades de ensino estruturado especializado para estudantes com espectro do autismo e com multideficiência e surdocegueira congênita.

Esses apoios são organizados pelo nível de desenvolvimento cognitivo, linguístico e social e pela idade dos estudantes, cujas escolas referências e unidades de ensino estruturadas concentram grupos de alunos, com especificidades e características pessoais que se assemelham. Compreendese, no entanto, que a organização da educação especial, no contexto educacional português, possui marcas históricas que ainda definem a organização da educação especial pelas orientações médicopsicológicas (JANNUZZI, 2006).

Nesse sentido, as adequações dos processos de ensino e aprendizagem desses sujeitos encontram-se fundamentadas nos princípios da diferenciação pedagógica e da flexibilização do currículo que integram as medidas educativas apresentadas na Figura 1, devendo ser adotadas mediante as especificidades de cada estudante.

Figura 1. Medidas educativas para o processo escolar de estudantes com NEE

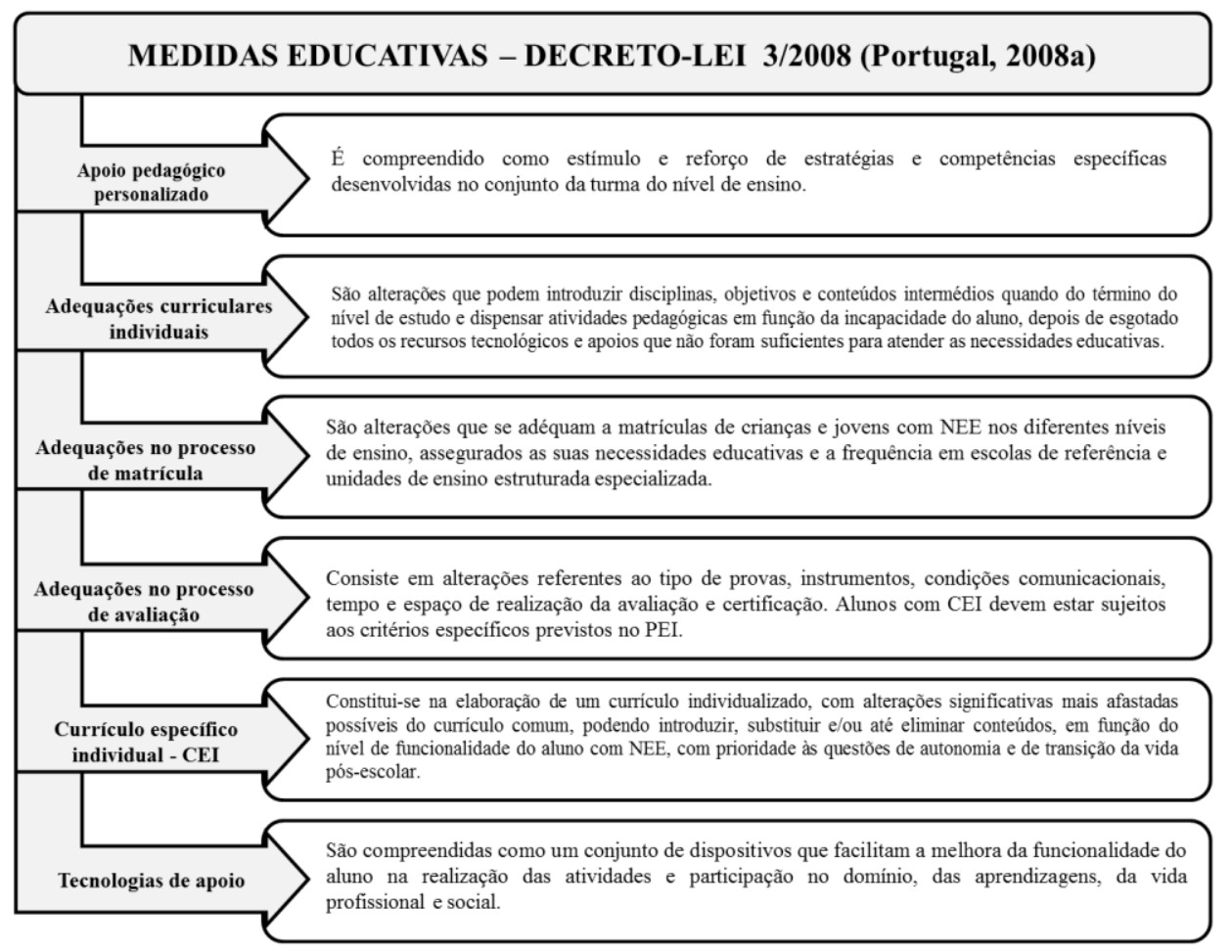

Fonte: Elaborado a partir do Decreto-Lei 3/2008 (PORTUGAL, 2008a).

Essas possibilidades alteram significativamente o currículo comum, partindo sempre de um nível de afastamento menor para o maior, com mudanças necessárias nas áreas curriculares e disciplinas, objetivos e competências, conteúdos e metodologias, modalidades de avaliação e outros aspectos fundamentais para dar condições reais de execução nas práticas curriculares, como a gestão do tempo e espaço, recursos humanos, materiais e também financeiros. Podem inclusive eliminar atividades de aprendizagem que se "revelem de difícil execução em função da 
incapacidade do aluno, só sendo aplicáveis quando se verifique que o recurso a tecnologias de apoio não é suficiente" (PORTUGAL, 2008a, art. 18, p. 159).

Nessa direção, a escolarização de estudantes com NEE ficam sujeitos a escolhas curriculares que prescrevem a organização de um CEI, sob parecer do conselho de docentes ou de turma, podendo substituir as competências previstas para cada nível de educação e ensino, com base no perfil de funcionalidade, com alterações que podem

[...] traduzir-se na introdução, substituição e ou eliminação de objectivos e conteúdos, [...] inclui conteúdos conducentes à autonomia pessoal e social do aluno e dá prioridade ao desenvolvimento de actividades de cariz funcional centradas nos contextos de vida, à comunicação e à organização do processo de transição para a vida pós-escolar. (PORTUGAL, 2008a, p. 159).

Esta medida educativa é a forma mais diferenciada possível prescrita para os percursos de alunos com deficiência de caráter permanente e considerada a mais distante ao nível do currículo comum.

Assim, compreende-se que os documentos oficiais analisados indicam uma sequência dos desdobramentos das políticas internacionais ratificadas e recontextualizadas localmente, incluindo todos os estudantes em escolas inclusivas, com prescrições voltadas à adequação e diferenciação curricular como possibilidades de alterar o currículo comum, mesmo frequentando turmas regulares do ensino básico, como detalha o Decreto-Lei 3/2008.

Os documentos políticos que orientam e prescrevem os processos escolares de alunos com deficiência no Brasil, foram identificados pela ênfase dada às políticas de inclusão e, mais precisamente, ao que se direciona à adequação e diferenciação curricular ou termos correlatos.

Quadro 2. Identificação das políticas de inclusão no Brasil (2008-2016).

\begin{tabular}{|c|c|}
\hline $\begin{array}{c}\text { ANO DE } \\
\text { PUBLICAÇÃO }\end{array}$ & DOCUMENTOS IDENTIFICADOS \\
\hline 2015 & Nota Técnica MEC/SECADI/DPEE 02/2015. \\
\hline 2015 & Nota Técnica MEC/SECADI/DPEE-SEB/DCEI 42/2015. \\
\hline 2015 & Lei 13.146/2015. \\
\hline 2014 & Lei 13.005/2014. \\
\hline 2014 & Nota Técnica MEC/SECADI/DPEE 04/2014. \\
\hline 2013 & Nota Técnica MEC/SECADI/DPEE 55/2013. \\
\hline 2012 & Portaria MEC/SECADI 25/2012. \\
\hline
\end{tabular}




\begin{tabular}{|c|c|}
\hline 2011 & Decreto 7.611/2011 \\
\hline 2010 & Resolução CNE/CEB 4/2010. \\
\hline 2010 & Nota Técnica MEC/SECADI/DPEE-SEB/DCEI 11/2010. \\
\hline 2009 & Resolução CNE/CEB 4/2009. \\
\hline 2009 & Decreto 6.949/2009. \\
\hline 2008 & Decreto Legislativo 186/2008. \\
\hline 2008 & Política Nacional de Educação Especial na Perspectiva da Educação Inclusiva- \\
\hline
\end{tabular}

Fonte: Elaborado a partir do site <http://portal.mec.gov.br/formacao/194-secretarias-112877938/secad-educacao-continuada223369541/17009-educacao-especial>.

As políticas de inclusão escolar no Brasil têm sido marcadas pelos acordos internacionais, desde a década de 1990, e, ao serem adotadas, “[...] ganham um desenho específico, alinhado com a história, a política, a economia e as disputas de diferentes forças que compõem a arena de luta política dos direitos da pessoa com deficiência" (SOUZA, 2013, p. 23), especialmente pela Declaração de Salamanca (UNESCO, 1994) e pela Convenção sobre os Direitos das Pessoas com Deficiência (ONU, 2006), que passaram a influenciar a formulação das políticas públicas de educação inclusiva em nível local, na garantia da educação para todos.

Esse movimento político nas duas últimas décadas no Brasil "é um bom exemplo das políticas globais a que os Estados nacionais estão sendo chamados a responder, decorrentes de agendas supranacionais e de todo um conjunto de forças externas aos países e seus territórios” (PLETSCH, LUNARDI-MENDES, 2015, p. 2).

Os documentos identificados no Quadro 2 vinculam-se as recomendações de políticas internacionais quanto a normatização de novas políticas educativas, como forma de regulamentar o contexto das práticas escolares, pela tradução das políticas (BALL, MAGUIRE; BRAUN, 2016), especificamente no AEE.

Confere que a Lei 13.146/2015 (BRASIL, 2015a), a Resolução CNE/CEB 04/2010 (BRASIL, 2010b) e a Lei 13.005/2014 (BRASIL, 2014b), embora tragam menções sobre a educação especial, o fazem em linhas mais gerais, como a garantia do AEE em todos os níveis, etapas e modalidades da educação, sem detalhar mais especificamente a execução de tais políticas no contexto das práticas curriculares. Do mesmo modo, o Decreto 6.949/2009 (BRASIL, 2009a) e o

\footnotetext{
${ }^{3}$ Revoga o Decreto 6.571/2008 (BRASIL, 2008c) instituído após a publicação da PNEEPEI (BRASIL, 2008a), regulamentou o parágrafo único do art. 60 da Lei de Diretrizes e Bases da Educação Nacional - LDBEN 9.394/1996 (BRASIL, 1996), que atribui ao poder público, a responsabilidade de adotar medidas alternativas para a ampliação do atendimento ao público-alvo da educação especial.
} 
Decreto Legislativo 186/2008, (BRASIL, 2008b) promulgam, aprovam e ratificam a Convenção sobre os Direitos das Pessoas com Deficiência (ONU, 2006), no âmbito brasileiro, que incidem sobre a educação como o principal locus da inclusão escolar, mas sem pormenorizar efetivas ações decorrentes de seus textos oficiais.

As Notas Técnicas 02/2015, 42/2015, 04/2014, 55/2013, 11/2010 (BRASIL, 2015c, 2015b, 2014a, 2010a), respectivamente, se constituem em fontes documentais, que formalizam situações ainda não cumpridas no âmbito da escolarização do público-alvo da educação especial, conforme a legislação vigente no Brasil. Estas Notas Técnicas orientam a garantia do AEE, pela implantação das SRM, podendo ser adquiridas pelas secretarias de educação dos estados, municípios e Distrito Federal, regulamentadas pela Portaria 25/2012 (BRASIL, 2012b).

Com isso, verifica-se que a PNEEPEI (BRASIL, 2008a), o Decreto 7.611/2011 (BRASIL, 2011) e a Resolução 04/2009 (BRASIL, 2009b) constituem-se em documentos oficiais marcadamente significativos e mais evidentes que dispõem sobre o sistema educativo inclusivo, calcados nos direitos educacionais das demandas de escolares com deficiência, propagadas pela evolução de matrículas, preferencialmente, na rede regular de ensino comum.

Considera-se imperativo a PNEEPEI (BRASIL, 2008a), no conjunto das fontes documentais, por se tratar de uma política nacional reconhecidamente como um marco divisor para a educação especial, que passa considerar os processos educativos do seu público-alvo como complementar e suplementar, além de definir suas principais diretrizes. Define o público-alvo da educação especial, como aquele que apresenta deficiência, transtorno globais de desenvolvimento e altas habilidades e superdotação, com o objetivo de

[...] assegurar a inclusão escolar (...) orientando os sistemas de ensino para garantir: acesso ao ensino regular, com participação, aprendizagem e continuidade nos níveis mais elevados do ensino; transversalidade da modalidade de educação especial desde a educação infantil até a educação superior; oferta do atendimento educacional especializado; formação de professores para o atendimento educacional especializado e demais profissionais da educação para a inclusão; participação da família e da comunidade; acessibilidade arquitetônica, nos transportes, nos mobiliários, nas comunicações e informação; e articulação intersetorial na implementação das políticas públicas. (BRASIL, 2008a, p. 14).

Ao prescrever o direito à inclusão escolar de estudantes com deficiência, a PNEEPEI (BRASIL, 2008a, p. 15) considera "àqueles que têm impedimentos de longo prazo, de natureza 
física, mental, intelectual ou sensorial" e indica sua escolarização preferencialmente na rede regular de ensino, reiterando o prescrito pela LDBEN 9.394/1996 (BRASIL, 1996).

A Resolução 4/2009 (BRASIL, 2009b) regulamenta o locus de atuação do AEE, "realizado prioritariamente, na sala de recursos multifuncionais da própria escola ou em outra escola de ensino regular, no turno inverso da escolarização, não sendo substitutivo às classes comuns", organizado pela institucionalização do projeto pedagógico da escola comum.

Figura 2. Organização institucional do AEE no projeto pedagógico da escola de ensino regular.

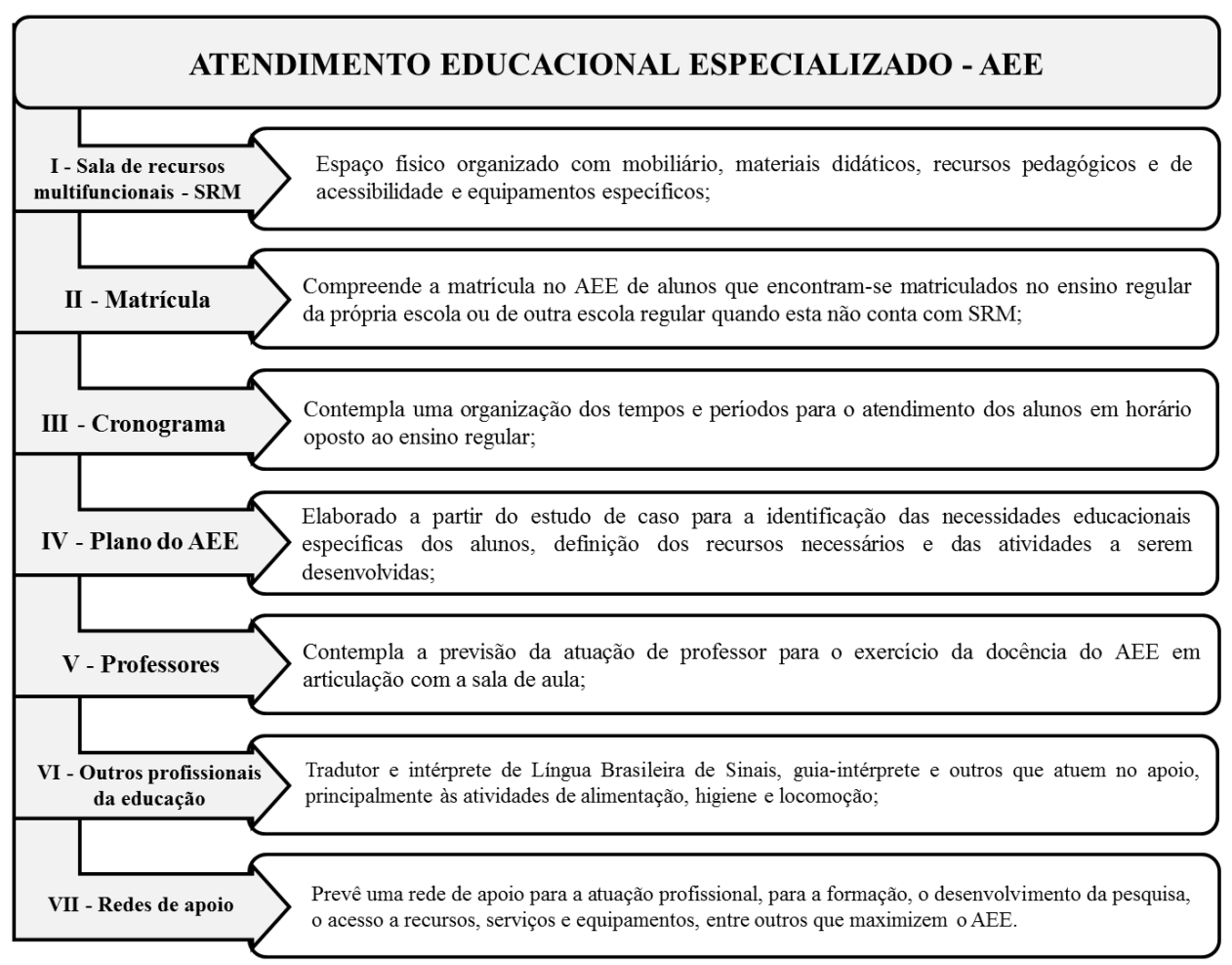

Fonte: Elaborado com base no artigo 10 da Resolução 4/2009 (BRASIL, 2009b).

As SRM são identificadas como serviço do AEE e caracterizadas como um espaço físico organizado, considerado pelas políticas de educação inclusiva brasileira como a máxima da inclusão escolar (PEREIRA, 2010), capaz de responder as mais variadas diversidades que constituem o contexto da sala de aula.

Desse modo, o AEE é concebido como um conjunto de atividades, recursos de acessibilidade e pedagógicos, organizados nas formas de complementar à formação dos estudantes com deficiência, transtorno globais de desenvolvimento, como apoio constante e com tempo limitado na frequência à SRM, e, suplementar à formação de estudantes com altas habilidades e superdotação (BRASIL, 2008a, 2009b, 2011). As atividades previstas mostram-se restritivas a um determinado espaço, que não substitui a escolarização, pelo que a diferenciação se dá nas práticas de atuação com os estudantes "constituindo oferta obrigatória dos sistemas de ensino e deve ser 
realizado no turno inverso ao da classe comum, na própria escola ou centro especializado" (BRASIL, 2008a, p. 16).

O acesso ao AEE é regulamentado pelo Decreto 7.611/2011 (BRASIL, 2011) e assegura o direito a dupla matrícula de cada estudante considerado público-alvo da educação especial, subsidiado pelo Fundo de Manutenção e desenvolvimento da Educação Básica e de Valorização dos Profissionais da Educação (Fundeb), computadas na classe de ensino comum e no AEE.

Destaca-se que a matrícula dos estudantes com deficiência não pode vincular-se a qualquer tipo de diagnóstico clínico, considerando que o AEE lida com questões educacionais e "o direito das pessoas com deficiência à educação não poderá ser cerceado pela exigência de laudo médico" como orienta a Nota Técnica 4/2014 (BRASIL, 2014a). Assim, a garantia do AEE em interface com o ensino comum, conforme os documentos analisados, não estabelecem outros critérios possíveis, como a redução de alunos por turmas e condições adequadas de apoio pedagógico em sala de aula.

A elaboração do plano de AEE, decorrente do estudo de caso, é pré-requisito e competência dos professores que atuam na SRM em articulação com professores do ensino comum, familiares e outros setores sociais, para vincular a frequência dos estudantes, com prescrições específicas e definidas pelos usos dos recursos e tipos de atividades que serão desenvolvidas. Entretanto, as competências do AEE acabam sendo atribuídas ao professor que atua na SRM.

Figura 3. Atribuições conferidas ao Professor na atuação do AEE.

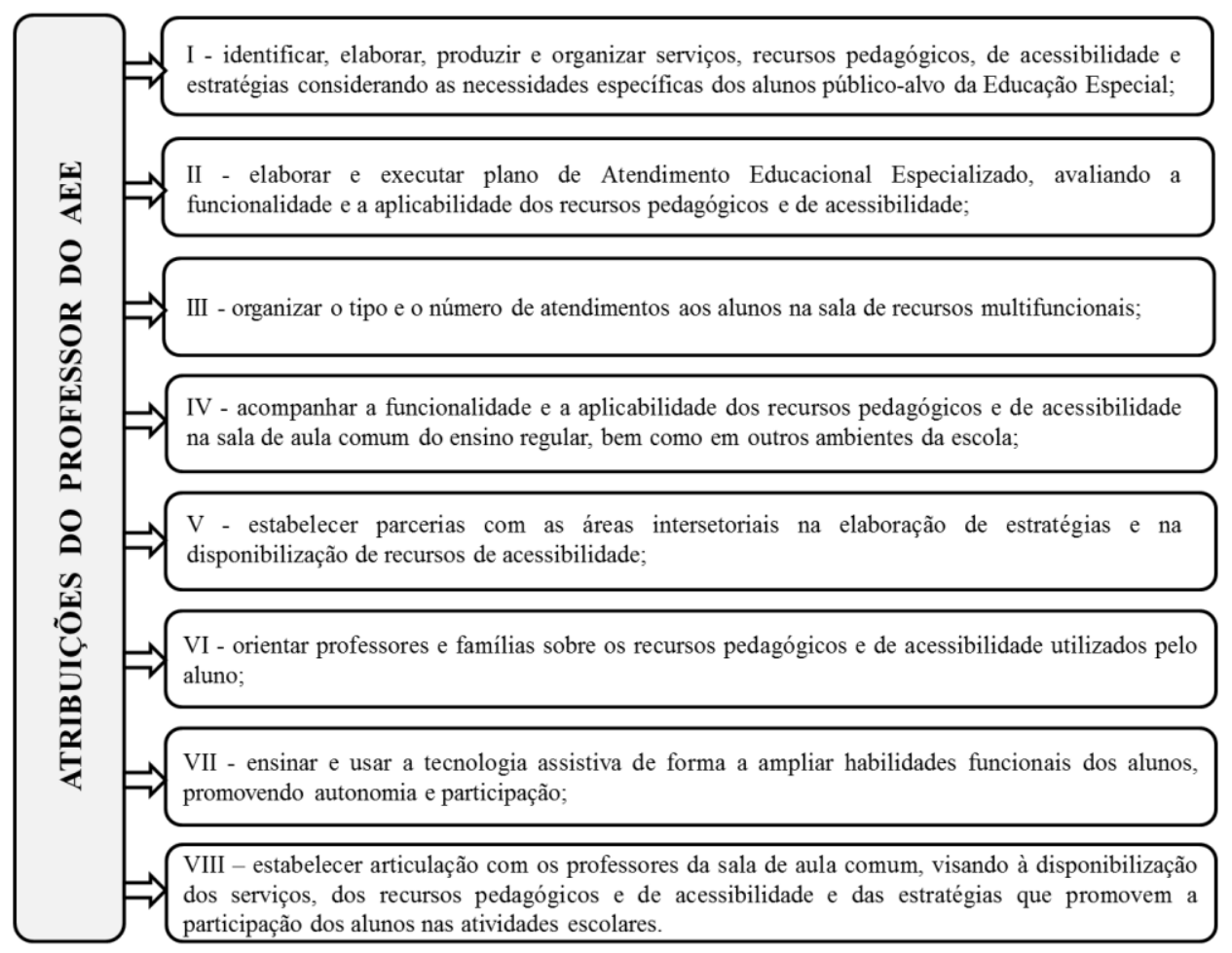

Fonte: Elaborado conforme art. 13, da Resolução 4/2009 (BRASIL, 2009b). 
Verifica-se que a competência atribuída ao professor do AEE centra-se no uso técnico dos recursos especializados e não nas questões pedagógicas que se articulam com a sala de aula comum. Numa versão comportamental, esta centralidade técnica dos recursos "pode estar relacionada à perspectiva psicopedagógica, [...] centradas na deficiência dos alunos e recursos diretamente vinculados a cada tipologia de deficiência” (MICHELS, 2011, p. 226). Além disso, o professor do AEE é caracterizado como o principal articulador e interlocutor das políticas de educação inclusiva e responsável pela inclusão escolar, sem considerar maior envolvimento de outros profissionais da educação e da gestão pública, assim como outras questões que também merecem atenção, como a instituição de políticas públicas para a educação em âmbito nacional e local.

Os estudos Bueno (2008), Garcia (2008), Mendes (2006), Kassar (2011), Souza (2013), Pletsch (2014) e Souza \& Pletsch (2017) indicam que as políticas de inclusão têm se constituído um mecanismo de disputas e de forças antagônicas, que expressam o direito à educação para estudantes com deficiência pelo princípio da educação inclusiva, mas, muitas vezes, sem considerar seus próprios percursos escolares, quanto o acesso aos conhecimentos curriculares.

Com isso, é razoável pensar que os sistemas de ensino são interpelados "a executarem as políticas em questão, de maneira que cada esfera administrativa vem se apropriando da política de inclusão ao seu modo" (MICHELS, 2011, p. 220), pela a implantação das SRM para o AEE, sem abordar os conhecimentos do currículo comum, pois este serviço restringe-se ao uso técnico de recursos tecnológicos, sem caracterizar-se em reforço escolar, questão que limita ampliar a escolarização dos alunos com deficiência para além do AEE.

Nos termos da complementação (BRASIL, 2008a, 2009b, 2011), a formação escolar de estudantes com deficiência fica submetida às prescrições normativas que não dão clareza das ações curriculares, menos ainda na possibilidade de transformação curricular (PACHECO, 2008, 2016) ou na adequação e diferenciação curricular na gestão em sala de aula (SOUSA, 2010; ROLDÃO, 1999, 2003a, 2003b), visto que estes sujeitos têm uma crescente participação nas estatísticas das matrículas nas escolas de ensino comum.

Corrobora-se com Ball, Maguire e Braun (2016, p. 14) que "as políticas raramente dizemlhe exatamente o que fazer, elas raramente ditam ou determinam a prática, mas algumas mais do que as outras estreitam a gama de respostas criativas”, em que as políticas de educação inclusiva descrevem um ideário de escola que acolhe todos os alunos, sem considerar as traduções e interpretações dos atores que as colocam em ação em relação à própria história e a realidade do contexto escolar. Por isso, compreende-se que as políticas sobre educação inclusiva requerem 
atenção especial tanto de quem as produz quanto de quem as coloca em execução nas práticas curriculares das escolas.

\section{CONSIDERAÇÕES FINAIS}

A educação inclusiva como princípio dos direitos humanos permanece um item importante na agenda da UNESCO, ONU e Banco Mundial ${ }^{4}$, além de outros organismos internacionais, que interferem diretamente nas decisões nacionais e nas práticas curriculares.

Notadamente, em Portugal o Decreto-Lei 3/2008 (PORTUGAL, 2008a) tem sido a maior expressão entre as políticas identificadas que orienta os projetos educativos e a organização dos espaços especializados. As escolas referências e as unidades de ensino estruturadas traduzem as prescrições da política de inclusão escolar e contemplam as adequações e diferenciação curricular por meio das medidas educativas que se articulam com a gestão da sala de aula comum. Dessas, o CEI é a alteração mais significativa e distante do currículo comum em termos da diferenciação curricular, reflexo da internacionalização das políticas desde a década de 1990, que tem condicionado os sistemas educativos garantir educação para todos e de qualidade, "através de um currículo apropriado" (UNESCO, 1994, grifo nosso). Mais recentemente, o supracitado decreto foi alterado pelo Decreto-Lei 54/2018 (PORTUGAL, 2018a), com a particularidade de substituir a noção de necessidades educativas especiais por educação inclusiva, numa perspectiva mais abrangente de todos os alunos, sem lhes impor uma educação especial mais específica.

Perrenoud (2000, p. 10) já sinalizava, que “a diferenciação da pedagogia e a individualização das trajetórias de formação estão, ou estarão, no centro das políticas da educação dos países desenvolvidos", como verificado nas fontes de documentos oficiais de Portugal, que passam, inevitavelmente, por uma agenda global.

No Brasil, a PNEEPEI (BRASIL, 2008a) tem sido referência para o desdobramento de outros documentos normativos que definem a instituição de ações e programas educativos na perspectiva da educação inclusiva, com a ênfase à Resolução 4/2009 (BRASIL, 2009b) e o Decreto n. ${ }^{\circ}$ 7.611/2011 (BRASIL, 2011). Estes documentos regulamentam a matrícula de alunos da educação especial, no ensino comum e no AEE e considera a SRM como local prioritário e privilegiado da inclusão escolar. É neste local que o professor especializado atua tecnicamente com

\footnotetext{
${ }^{4}$ Relatório Mundial sobre a Deficiência (World Report on Disability). The World Bank. Tradução: Secretaria dos Direitos da Pessoa com Deficiência do Governo do Estado de São Paulo, 2011.
} 
os recursos tecnológicos disponíveis, sem qualquer objeção a sua atuação docente de cunho pedagógico, menos ainda, aos conhecimentos curriculares.

Nesse sentido, verifica-se que a justiça curricular na escolarização de estudantes com deficiência passa pela possibilidade de minimizar ou até excluir conteúdos do currículo comum (Portugal), expresso atualmente pelo Decreto-Lei 55/2018 (PORTUGAL, 2018b), pelo documento curricular Aprendizagens Essenciais, bem como pela frequência de alunos no contraturno escolar, numa sala específica definida como recursos multifuncionais (Brasil). Contudo, não encontramos evidências mais explícitas sobre o acesso aos conhecimentos escolares, questão considerada fundamental para o acesso a escolarização de todos os alunos e a garantia da justiça curricular.

Compreende-se que uma decisão política pode ser justa para um determinado público escolar e injusta para outro. Por isso, um currículo centrado no 'conhecimento' torna-se mais coerente com uma política de justiça social no âmbito da educação, como destaca (YOUNG, 2007, 2013, 2016). Assim, é preciso analisar se o conhecimento escolar se constitui em um direito "para poucos ou para todos" (YOUNG, 2016, p. 24), quando se trata de uma política de inclusão escolar que pressupõe uma educação para todos, com prioridade na escola de ensino comum.

Conclui-se, portanto, que as políticas de inclusão escolar no ápice da globalização, mostramse atuantes nos dois contextos nacionais, por ter encontrado em ambos "uma raiz local, uma imersão cultural específica” (SANTOS, 1997, p. 108), para sua tradução na perspectiva da educação inclusiva. Uma das similaridades encontradas entre os documentos oficiais dos contextos brasileiro e português está na organização de um espaço específico para o atendimento de um público também específico, restrito à educação especial. Contudo, o diferencial está no detalhamento das medidas educativas definidas pela diferenciação curricular, para os percursos de escolarização dos alunos conforme suas necessidades. Tais definições levam a entender que as recomendações das políticas internacionais para a educação inclusiva são interpretadas e traduzidas localmente conforme a realidade de cada contexto e se diferenciam pelas decisões curriculares empreendidas (BOWE; BALL; GOLD, 1992; BALL; MEGUIRE; BRAUN, 2016), tanto no Brasil quanto em Portugal.

Com isso, a internacionalização das políticas educacionais tende a uniformizar cada vez mais os sistemas educativos, na medida em que orienta e financia a educação (AKKARI, 2011), mesmo que a tradução se diferencie pela interpretação dos atores que as colocam em atuação (BALL, MAGUIRE, BRAUN, 2016). É nesse movimento de decisão política e da sua tradução que uma política na perspectiva da educação inclusiva ganha forma com a atuação dos diferentes atores envolvidos, tanto de quem a escreve quanto daqueles que a coloca em atuação, e que, de algum 
modo, interferem nas condições de escolarização dos alunos com deficiência, ao mesmo tempo, pode distanciar a garantia de justiça curricular. 


\section{REFERÊNCIAS}

AKKARI, A. Internacionalização das políticas educacionais: transformações e desafios. Petrópolis: Vozes, 2011.

BALL, S. J. Diretrizes políticas globais e relações políticas locais em educação. Currículo sem Fronteiras, v. 1, n. 2, p. $99-116$, dez. 2001

; MAGUIRE, M.; BRAUN, A. Como as escolas fazem as políticas: atuação em escolas secundárias. Trad.: Janete Bridon. Ponta Grossa: Editora UEPG, 2016.

BARDIN, L. Análise de conteúdo. Trad.: Luís Antero Reto e Augusto Pinheiro. Lisboa: Portugal, Edições 70, LDA, 2009.

BOWE, R.; BALL, S. J.; GOLD, A. Reforming Education and Changing Schools: case studies in policy sociology. London: Routledge, 1992.

BUENO, J. G. S. As políticas de inclusão escolar: uma prerrogativa da educação especial? In: BUENO, J. G. S.; MENDES, G. M. L.; SANTOS, R. A. (Orgs.). Deficiência e escolarização: novas perspectivas de análise. Araraquara: Junqueira \& Marin; Brasília: CAPES, 2008. p. 43-63.

CONNELL, R. W. Escuelas y justicia social. Madrid: Ediciones Morata, 1997.

GARCIA, R.M.C. Políticas inclusivas na educação: do global ao local. In: BAPTISTA, C. R.; CAIADO, K.R.M.; JESUS, D.M. (Orgs.). Educação especial: diálogo e pluralidade. Porto Alegre: Mediação, 2008. p. 11-23.

JANNUZZI, G.S.M. A educação do deficiente no Brasil: dos primórdios ao início do século XXI. 2. ed. Campinas/SP: Autores Associados, 2006.

KASSAR, M. C. M. Percursos da constituição de uma política brasileira de educação especial inclusiva. In: Revista Brasileira de Educação Especial, v. 17, n. esp. 1, p. 41-58, 2011, maio/ago. Disponível em: <https://doi.org/10. 1590/S1413-65382011000400005>. Acesso em: 12 abr. 2018.

MENDES, E.G. A radicalização do debate sobre inclusão escolar no Brasil. Revista Brasileira de Educação, Campinas, v. 11, n. 33, p. 387-405, 2006.

MICHELS, M.H. O que há de novo na formação de professores para a Educação Especial? Revista Educação Especial, Santa Maria, v. 24, n. 40, p. 219-232, maio/ago. 2011. Disponível em: <http://www.ufsm.br/revista educacaoespecial>. Acesso em: 14 abr. 2018.

PACHECO, J.A. Notas sobre Diversificação/Diferenciação curricular em Portugal. InterMeio: Revista do PPGE, Campo Grande: MS, v. 14, n. 28, Jul/Dez, 2008, p. 178-187.

. Para a noção de transformação curricular. Cadernos de Pesquisa, v. 46 n. 159, p. 64-77, jan./mar. 2016

PEREIRA, C. D. A oferta de serviços de educação especial no município de Braço do Norte - SC. 155 f., Dissertação (Mestrado em Educação) - Universidade Federal de Santa Catarina - UFSC, Florianópolis/SC, 2010. Disponível em: <http://repositorio.ufsc.br/xmlui/handle/123456789/91655>. Acesso em: 20 set. 2017.

PERRENOUD, P. Pedagogia diferenciada: das intenções à ação. Trad. Patrícia Chitoni Ramos. Porto Alegre: Artes Médicas Sul, 2000.

PLETSCH, M. D.; LUNARDI-MENDES, G. M. Entre políticas e práticas: Os desafios da educação inclusiva no Brasil. Dossiê Educação Especial: Diferenças, currículo e processos de ensino e aprendizagem II. Editoras convidadas: PleTSCH, M. D.; LUNARDI-MENDES, G. M. Archivos Analíticos de Políticas Educativas/Education Policy Analysis Archives, v. 23, n. 27, p. 1-12, 2015. Disponível em: 〈http://dx.doi.org/10.14507/epaa.v23.2003〉. Acesso em: 10 set. 2016.

A escolarização de pessoas com deficiência intelectual no Brasil: da institucionalização às políticas de inclusão (1973-2013). Arquivos Analíticos de Políticas Educativas, v. 22, n. 81. Dossiê Educação Especial: diferenças, currículo e processos de ensino e aprendizagem. Editoras convidadas: PLETSCH, M. D. \& LUNARDIMENDES, G. M., 2014, p. 1-29. Disponível em: 〈http://dx.doi.org/10.14507/epaa.v22n81.2014>. Acesso em: 10 set. 2016.

ROLDÃO, M.C. Diferenciação curricular e inclusão. In: RODRIGUES, David. (Org.). Perspectivas sobre a inclusão: da educação à sociedade. Porto: Porto Editora, 2003b. p. 151-165.

Diferenciação curricular revisitada: Conceito, discurso e práxis. Porto: Porto Editora, 2003a. 
ROLDÃO, M.C. Os Professores e a Gestão do Currículo: Perspectivas e Práticas em Análise. Porto: Porto Editora, 1999.

SANTOS, B.S. Uma concepção multicultural de direitos humanos. Lua Nova, n. 39, p. 105-124, 1997. Disponível em: <http://dx.doi.org/10.1590/S0102-64451997000100007>. Acesso em: 12 abr. 2018.

SILVA, R. R. D. Revisitando a noção de justiça curricular: problematizações ao processo de seleção dos conhecimentos escolares. Educação em Revista. 2018, vol. 34, p. 16882, jan. 18, 2018. Disponível em: <http://dx.doi.org/ 10.1590/0102-4698168824>. Acesso em: 15 abr. 2018.

SOUSA, F. Diferenciação curricular e deliberação docente. Porto: Porto Editora, 2010.

SOUZA, F. F. Políticas de educação inclusiva: análise das condições de desenvolvimento dos alunos com deficiência na instituição escolar. 277f. Tese de Doutoramento Universidade Estadual de Campinas/UNICAMP: Campinas: São Paulo, 2013.

; PLETSCH, M. D. A relação entre as diretrizes do Sistema das Nações Unidas (ONU) e as políticas de Educação Inclusiva no Brasil. Ensaio: Avaliação e Políticas Públicas em Educação. 2017, vol. 25, n. 97, p. 831-853, maio. 2017. Disponível em: 〈http://dx.doi.org/10.1590/s0104-40362017002500887>. Acesso em: 20 out. 2017.

YOUNG, M. F. Abordagem baseada no conhecimento. In: FAVACHO, A.; PACHECO, J. A.; SALES, S. Currículo: conhecimento e avaliação. Editora CRV, 2013. 276p.

. Para que servem as escolas? In: Revista Educação \& Sociologia. Campinas, v. 28, n. 101, p. 1287-1302, set./dez. 2007. Disponível em: <http://www.scielo.br/pdf/es/v28n101/a0228101.pdf〉. Acesso em: 17 maio 2018. 18-37, 2016.

Por que o conhecimento é importante para as escolas do século XXI? Cadernos de Pesquisa, v. 46, n. 159, p.

\section{FONTES DOCUMENTAIS}

BANCO MUNDIAL. Relatório Mundial sobre a Deficiência (World Report on Disability). The World Bank. Tradução: Secretaria dos Direitos da Pessoa com Deficiência do Governo do Estado de São Paulo, 2011. Disponível em: <http://www.pessoacomdeficiencia.sp.gov.br/usr/share/documents/RELATORIO_MUNDIAL_COMPLETO.pdf>. Acesso em: 20 out. 2017.

BRASIL. Decreto Legislativo 186, de 9 de julho de 2008, Aprova o texto da Convenção sobre os Direitos das Pessoas com Deficiência e de seu Protocolo Facultativo, assinados em Nova Iorque, em 30 de março de 2007. Diário Oficial da União, Brasília, 2008b.

. Decreto 6.571, de 17 de setembro de 2008. Dispõe sobre a educação especial, o atendimento educacional especializado, regulamenta o parágrafo único do art. 60 da Lei 9.394/1996. Diário Oficial da União. Brasília, 2008c.

. Decreto 6.949, de 25 de agosto de 2009, promulga a Convenção Internacional sobre os Direitos das Pessoas com Deficiência - ONU. Diário Oficial da União, Brasília, 2009a.

. Decreto 7.611, de 17 de novembro de 2011. Dispõe sobre a educação especial, o atendimento educacional especializado. Diário Oficial da União. Brasília, 2011.

. Lei de Diretrizes e Bases da Educação Nacional - Lei 9.394/96 de 20 de dezembro de 1996. Estabelece as diretrizes e bases da educação nacional. Diário Oficial da União. Brasília, DF, 23 dez. 1996.

. Lei 13.005, 25 de junho de 2014. Aprova o Plano Nacional de Educação - PNE. Diário Oficial da União. Brasília, 2014b.

. Lei 13.146, de 06 de junho de 2015. Institui a Lei Brasileira de Inclusão da Pessoa com Deficiência. Diário Oficial da União. Brasília, 2015a.

MEC/CNE. Resolução CNE/CEB 04, de 13 de junho de 2010. Define Diretrizes Curriculares Nacionais Gerais para Educação Básica. Diário Oficial da União. Brasília, 2010 b.

. MEC/CNE. Resolução 04, de outubro de 2009. Institui diretrizes operacionais para o atendimento educacional especializado na Educação Básica, modalidade Educação Especial. Diário Oficial da União. Brasília, 2009 b.

. MEC/SEESP. Política Nacional de Educação Especial na Perspectiva da Educação inclusiva. Brasília: MEC/SECADI, v.4, p. 7-17, jan./jun. 2008 ${ }^{\mathrm{a}}$. 
BRASIL. MEC/SEESP. Portaria Normativa 13 de 24 de Abril/2007, Dispõe sobre a criação do Programa de Implantação de Salas de Recursos Multifuncionais. Diário Oficial da União. Brasília, 2007.

. Nota Técnica 02, 4 de agosto de 2015, MEC/SECADI/DPEE, 2015c.

. Nota Técnica 04, 23 de janeiro de 2014, MEC/SECADI/DPEE, 2014a.

Nota Técnica 11, 7 de maio de 2010, MEC/SECADI/DPEE-SEB/DCEI, 2010a.

. Nota Técnica 42, 16 de junho de 2015, MEC/SECADI/DPEE-SEB/DCEI, 2015 b.

. Nota Técnica 55, 10 de maio de 2013, MEC/SECADI/DPEE, 2013.

Portaria 25, 19 de junho de 2012, MEC/SECADI, 2012 b.

ONU. Convenção Internacional das Nações Unidas sobre os Direitos das Pessoas com Deficiência. Nova Iorque: Estados Unidos, 2006.

PORTUGAL. Decreto-Lei 176/2012, de 2 de agosto, de 2012. Diário da República, 1. a série, n. 149, 2 ago. 2012 , 2012a.

. Decreto-Lei 281/2009, 6 Outubro. Diário da República, 1. a série, n. 193, 6 Out. 2009c.

Decreto-Lei 3/2008. de 7 de janeiro de 2008. Diário da República, 1. ${ }^{a}$ série, n. 4, 7 Jan. 2008 a.

. Decreto-Lei 54/2018. Diário da República, 1. a série, n. 129, 6 de jul. 2018a.

. Decreto-Lei 55/2018. Diário da República, 1. a série, n. 129, 6 jul. 2018 b.

. Lei 21/2008, de 12 de maio, de 2008. Diário da República, 1. a série, n. 91, 12 maio 2008 b.

. Lei 46/1986, de 14 de Outubro. Lei de Bases do Sistema Educativo - Conselho Nacional de Educação. Diário da República, 1986.

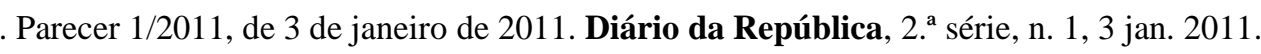

Portaria n. 201-C/2015, de 10 de julho. Diário da República, 1. a série, n. 133, 10 jul. 2015 b.

fev. 2015a

. Resolução da Assembleia da República 17/2015, de 06 de fevereiro. Diário da República, 1. a série, n. 35,19

. Resolução da Assembleia da República 56, de 07 de maio de 2009. Convenção sobre os Direitos das Pessoas com Deficiência, aprovada pela Assembleia Geral da ONU. Diário da República, 1. a série, n. 146, 30 jul. 2009 a.

Resolução da Assembleia da República 57, de 07 de maio de 2009. Aprova o Protocolo Opcional à Convenção sobre os Direitos das Pessoas com Deficiência, adoptado em Nova Iorque em 30 de Março de 2007. Diário da República, 1. ${ }^{a}$ série, n. 146, 30 jul. 2009b.

UNESCO. Conferência Mundial de Educação para Todos. Declaração mundial sobre educação para todos e Plano de ação para satisfazer as necessidades básicas de aprendizagem. Jomtien: Tailândia, 1990.

Declaração de Salamanca: Sobre Princípios, Políticas e Práticas na Área das Necessidades Educativas Especiais: Salamanca: Espanha, 1994. 


\section{RESUMO}

Políticas de inclusão escolar têm sido disseminadas pela internacionalização das políticas educacionais. Este texto analisa documentos políticos de inclusão escolar que regulamentam a escolarização de alunos com deficiência da educação básica como garantia de justiça curricular. Utilizou-se documentos oficiais delimitados entre 2008 e 2016 do Brasil e de Portugal. Conclui-se que ambos os países seguem recomendações internacionais, mas as decisões locais se diferenciam na definição curricular das medidas educativas e se assemelham na definição do público restrito à educação especial. Verifica-se que os conhecimentos escolares não fazem parte das discussões dos textos políticos analisados, consequentemente, não estão ao alcance de todos e a garantia de justiça curricular fica comprometida.

Palavras-chave: Políticas de inclusão escolar. Justiça curricular. Escolarização de alunos com deficiência.

\section{POLICIES OF SCHOOL INCLUSION IN BRAZIL AND PORTUGAL: CHALLENGES FOR CURRICULAR JUSTICE}

\section{ABSTRACT}

Policies for school inclusion have been disseminated through the internationalization of educational policies. This text analyzes political documents of school inclusion that regulate the schooling of students with disabilities of basic education as a guarantee of curricular justice. It was used official documents delimited between 2008 and 2016 from Brazil and Portugal. It is concluded that both countries follow international recommendations, but local decisions differ in the curricular definition of educational measures and resemble the definition of the public restricted to special education. It is verified that the school knowledge is not part of the discussions of the analyzed political texts, therefore, they are not within reach of all and the guarantee of curricular justice is compromised.

Keywords: Policies of school inclusion. Curricular justice. Schooling of students with disabilities.

\section{POLÍTICAS DE LA INCLUSIÓN ESCOLAR EN BRASIL Y PORTUGAL: RETOS PARA LA JUSTICIA CURRICULAR}

\section{RESUMEN}

Las políticas de inclusión escolar se han diseminado por la internacionalización de las políticas educativas. Este texto analiza documentos políticos de inclusión escolar que regulan la escolarización de alumnos con discapacidad en la educación básica como garantía de justicia curricular. Se utilizó documentos oficiales limitados entre 2008 y 2016 en Brasil y Portugal. Se concluye que ambos países siguen recomendaciones internacionales, pero las decisiones locales se diferencian en la definición curricular de las medidas educativas y se asemejan en la definición del público restringido a la educación especial. Se verifica que los conocimientos escolares no forman parte de las discusiones de los textos políticos analizados, en consecuencia, no están al alcance de todos y la garantía de justicia curricular queda comprometida.

Palabras-clave: Políticas de la inclusión escolar. Justicia curricular. Educación de estudiantes con discapacidad. 